\title{
ISIDRO PARGA PONDAL, O SEMINARIO DE ESTUDOS GALEGOS E O LABORATORIO DE XEOQUÍMICA DA UNIVERSIDADE DE SANTIAGO
}

\author{
Francisco J. Leonardo Docanto \\ franleonardo@yahoo.es
}

\begin{abstract}
RESUMO
Isidro Parga Pondal foi un dos científicos máis importantes que traballou na Universidade de Santiago. A súa valía como investigador fixo que esta institución, o Seminario de Estudos Galegos e a Fundación Nacional para Investigaciones Científicas y Ensayos de Reformas subvencionasen o establecemento do primeiro laboratorio de Xeoquímica fundado en España, que foi dirixido por Parga. Neste laboratorio se realizaron importantes traballos, moitos encamiñados á busca de aplicacións prácticas que permitisen o establecemento de novas industrias en Galicia. Neste artigo se explica a orixe deste Laboratorio, as súas características e as actividades que levaba a cabo, así como os traballos que quedaron sen facer pola expulsión de Parga da Universidade ao comezo da Guerra Civil.
\end{abstract}

PALABRAS CLAVE: Isidro Parga Pondal. Xeoquímica. Xeoloxía. Historia da ciencia. Galicia.

\section{PARGA PONDAL, THE SEMINARY OF GALICIAN STUDIES AND THE LA- BORATORY OF GEOCHEMISTRY, UNIVERSITY OF SANTIAGO}

\begin{abstract}
Isidro Parga Pondal was one of the most important scientists who worked in the University of Santiago. His value as researcher has made that this institution, the Seminary of Galician Studies and the National Foundation for Scientifics Researchers and Trials of Reforms subsidized the establishment of the first laboratory of Geochemistry founded in Spain, which was directed by Parga. This laboratory made significant researches, a lot of them designed to search for practice applications that allowed the establishment of new industries in Galicia. This paper explains the origin of this laboratory, its characteristics, the activities which carried out and the investigations not ended because of the Parga's expulsion of the University at the beginning of the Civil War.
\end{abstract}

KEY WORDS: Isidro Parga Pondal. Geochemistry. Geology. History of science, Galicia. 


\section{INTRODUCIÓN}

O Seminario de Estudos Galegos (SEG), tal e como relata detalladamente Mato $^{1}$, foi unha institución que tivo a súa orixe no curso 1923-24, no que un grupo de estudantes universitarios amantes de $\mathrm{Galicia}^{2}$, tras conversar acerca da posibilidade de crear un centro cultural no que traballasen sobre as súas inquietudes, puxéronse en contacto co catedrático de Filosofía Armando Cotarelo Valledor. Tras unha reunión en casa deste, conseguen canalizar os seus propósitos cara a un modelo determinado de organización cultural. Días despois, o 21 de outubro de 1923, queda constituído o Seminario, realizándose a primeira reunión seis días despois da súa fundación, na antiga Facultade de Filosofía e Letras. Os creadores do SEG inspiráronse noutras institucións existentes que promovían a investigación e o interese polo país, tal como narrou un dos iniciadores do Seminario, José Filgueira Valverde:

...En Galicia era necesario este movimiento de colaboración docente e investigador. (...) Hubimos de inspirarnos en el ejemplo de labor de cultura y patriotismo de la Sociedad de Estudios Vascos, institución que tanto ha laborado por la valorización cultural de aquel país (...). Del Instituto de Estudios Catalanes, exaltador ferviente de las virtudes de aquella tierra. De la Junta de Ampliación de Estudios, que como se sabe va a la cabeza del movimiento intelectual del momento. Todo ello impeliónos a abordar esta obra. Paralelamente quisiéramos suscitar una respuesta en el pueblo gallego a nuestra labor, cual la han obtenido estos otros centros de labor que menciono... ${ }^{3}$

Para abarcar todas as áreas da cultura galega, os estudos realizados no Seminario dividíanse en diferentes Seccións, cuxo número foi variando ao longo da súa historia. No ano 1923 propúñanse dez: Historia, Arte, Lingua e Literatura, Ciencias Sociais, Ciencias Naturais, Ciencias Médicas, Etnografía, Biografías, Folclore e Bibliografía.

1 Mato, A. (2001), O Seminario de Estudos Galegos na documentación que garda o Instituto Padre Sarmiento, Sada-A Coruña. Publicacións do Seminario de Estudos Galegos, Ed. do Castro.

2 Entre eles Fermín Bouza Brey, Xosé Filgueira Valverde, Xulián Manuel Magariños Negreira, Ramón Martínez López, Lois Tobío Fernández, Wenceslao Requejo Buet, Ramón Francisco Romero Lema, Xosé Pena y Pena y Alberto Vidán Freiria.

3 GonzÁlez, X. (1928), Una visita al Seminario de Estudios Gallegos. Céltiga, 74. O artigo non presenta as follas numeradas. Esta referencia corresponde ás dúas primeiras páxinas do mesmo. 
Para o ingreso no Seminario eran necesarios unha serie de requisitos, como consta nos Estatutos da organización: a proposta previa dun $\operatorname{socio}^{4}$, a súa admisión na reunión seguinte á que se produciu a proposta e a lectura dun traballo orixinal e inédito, condicións que foron variando ao longo do tempo, segundo narra o propio Isidro Parga Pondal ${ }^{5}$ : «A primeira obriga dos membros do Seminario era a de presentaren un traballo anual, mais despois esta norma foi evolucionando ca publicación dos Arquivos, donde se publicaban os traballos presentados nas diferentes sesións, ou nas xuntanzas».

O Seminario de Estudos Galegos tratábase dunha institución directamente relacionada coa Universidade, tanto polo alto número de socios que eran alumnos ou profesores da mesma, como pola utilización das súas instalacións para reunións ou investigacións. O director do Seminario no ano 1928, Salvador Cabeza de León, resume estas relacións da seguinte forma ${ }^{6}$ : «Seminario y Universidad se relacionan grandemente. Se complementan pudiéramos decir, se completan, a pesar de la autonomía en que vive el Seminario. (...) Pudiera

4 Tal como indica Mato, A. (2001), p. 33, os estatutos do Seminario establecían tres tipos diferentes de socios: os asesores (residentes en Compostela e propostos pola Sección Directora), os numerarios (que leran un traballo de ingreso) e os correspondentes (colaboradores ou socios que non leran o traballo de ingreso).

5 Parga, I. (1978), Isidro Parga Pondal, Testemuñas e perspectivas en homenaxe ao Seminario de Estudos Galegos. Cadernos do Laboratorio de Formas de Galicia, 5, p. 65-67, O Castro-Sada, Ediciós do Castro.

Isidro Parga Pondal (Laxe, 1900 - A Coruña, 1986) licenciouse en Ciencias Químicas na Universidade Central e recén rematada a carreira obtivo unha plaza de profesor auxiliar de Análise Química na Facultade de Ciencias da Universidade de Santiago, cargo que desempeñou ata a súa expulsión da Universidade en 1936. Durante este periodo obtivo dúas importantes bolsas, unha da Junta para la Ampliación de Estudios, que lle permitiu estudar xeoquímica e xeoloxía en Zürich entre os anos 1930 e 1931, e outra da Asociación Española de Fabricantes de Cemento, desfrutada en Berlín entre 1932 e 1933. Estas bolsas lle permitiron traballar cos mellores xeoquímicos e xeólogos do mundo naqueles anos, como Paul Niggli, en Zürich, ou Hans Kühl en Berlín, convertindo a Parga no xeoquímico máis destacado co que contara España ata o momento. A súa expulsión da Universidade Compostelana no ano 1936, acusándoo de galeguista e ideoloxía de esquerdas, estivo influenciada en parte pola súa pertenza ao Seminario e a súa amizade con destacados galeguistas, como Alfonso Daniel Rodríguez Castelao. Retirado á súa vila natal, fundou alí o Laboratorio Xeolóxico de Laxe, que entre 1940 e 1965 foi a única institución galega dedicada ao estudo da Xeoloxía (Vidal, J. R. (2009) El Laboratorio Geológico de Lage, Tierra y tecnología, $\mathrm{n}^{\mathrm{o}} 35,73-80$, p. 73). Desde este Laboratorio levou a cabo importantes traballos, como a publicación, en colaboración co IGME, de mapas xeolóxicos de Galicia, nos que aportou gran cantidade de novos e importantes datos.

6 GonZÁlez, X. (1928), p. 2. 
decirse que éste es un centro de preparación de alumnos de la Universidad en las labores de investigación».

\section{COMEZO DAS INVESTIGACIÓNS XEOQUÍMICAS DE ISIDRO PARGA PONDAL}

A relación de Isidro Parga Pondal co SEG ten a súa orixe en 1925, pois na acta da reunión do Seminario do día 14 de novembro dese ano recóllese a intención do Presidente do Seminario de crear unha Sección de Xeoquímica, que sería dirixida por Parga, que aínda non era socio. A súa entrada prodúcese da man de Luis Iglesias Iglesias, compañeiro seu na Facultade de Ciencias e membro do Seminario desde o día 22 de xaneiro de 1926.

A entrada do mozo profesor no Seminario ten lugar o día 30 de outubro de 1926, coa lectura do seu traballo de investigación «Datos para la geoquímica de Galícia. El contenido en yodo de las principales algas marinas de las costas de Galicia». A pesares de tratarse da primeira publicación de Parga, amosa unha correcta estruturación no contido do traballo. Conta cunha completa introdución, formada por dúas partes, «Algunos datos sobre la Geoquímica»e «Historia geoquímica del iodo», na que inclúe o estado de coñecementos sobre o tema, tanto no campo da xeoquímica en xeral como do iodo en particular, e os obxectivos da investigación. A continuación, no apartado «Análisis del yodo en las algas de Galicia. Métodos, consecuencias y comparación de resultados», explica claramente as especies analizadas, a súa orixe, data de recolleita, etc. Na parte experimental conta con detalle o protocolo empregado, por que elixiu este e non outro, as diferencias con outros métodos existentes, etc. Na discusión explica os seus resultados, xustificándoos polo miúdo, mentres que nas conclusións non se limita aos resultados experimentais obtidos, se non que os relaciona con aplicacións prácticas que puideran ter unha gran importancia económica para Galicia. Por último, a pesares do limitado dos recursos da Facultade de Ciencias, o autor manexa unha completa bibliografía, en castelán, alemán e francés, sobre xeoquímica, o iodo, as algas e diversos tratados de química analítica.

As algas analizadas foran recollidas nunha serie de recorridos pola costa de Galicia nas que Parga ía acompañado da súa dona, Avelina Peinador. Segundo conta o único fillo vivo do matrimonio, para obter as cinzas que logo eran analizadas en Santiago, as algas foron queimadas en Laxe, algunhas no xardín da casa onde naceu e noutras partes do pobo:«Eu acórdome de pequeno que ía coa miña nai a onde está agora o muelle grande, que eran rochas, e había unha fogueira como a metade desta terraza de grande, para xuntar as 
cinzas das algas. Había un pesco que había ido a coller as algas e as queimaba alí, para que meu pai collera as cinzas e as analizara». ${ }^{7}$

Parga clasificou estes organismos e os analizou seguindo os métodos que atopou na bibliografía á que podía ter acceso desde a Facultade de Ciencias, en cuxo laboratorio de Química Analítica realizou as análises.

Este traballo, publicado en El Eco Franciscano en $1927^{8}$, consta de 30 páxinas, extensión moi superior á maioría das súas publicacións posteriores. Comeza cunha breve presentación na que indica o estado do estudio xeoquímico de España, que está sen facer, e presenta os seus agradecementos á Facultade de Ciencias Químicas (sic) e ao Seminario de Estudios Gallegos (sic), polo seu interese nos estudios realizados. Personifica este agradecemento no Decano da Facultade, Mariano Álvarez Zurimendi, e en dous dos membros do SEG: José Vázquez Garriga, alumno de Parga, e en Juan José Barcia Goyanes, profesor auxiliar temporal de Anatomía da Facultade de Medicina, o que nos leva a pensar que probablemente desenroláronse parte das análises deste investigación na devandita facultade.

O primeiro apartado deste traballo leva por título «Algunos datos sobre la Geoquímica» ${ }^{9}$, no que o autor fai algunhas consideracións sobre o ciclo xeoquímico dos elementos, consideracións que, segundo o propio Isidro, constituíron o xerme a partires do cal desenrolouse a súa futura carreira científica ${ }^{10}$. Estas «consideraciones» pódense dividir nun primeiro apartado, no que o científico realiza unha definición da Xeoquímica: «La Geoquímica estudia los elementos químicos de la corteza terrestre, considerándolos aisladamente, indagando su historia, o sea su distribución en el espacio y tiempo y tratando de penetrar las oscuras relaciones existentes entre la extructura de los átomos de los elementos y su abundancia en la corteza de la tierra $(\ldots) \gg .{ }^{11}$

7 Entrevista grabada co fillo de Isidro Parga Pondal, Jorge Parga Peinador, en Laxe, o día 16/8/2010.

8 PARga Pondal, I. (1927), Datos para la Geoquímica de Galicia. El contenido en yodo de las principales algas marinas de las costas de Galicia, Santiago. Tip. de El Eco Franciscano.

Esta publicación relixiosa editaba frecuentemente traballos científicos. Outros exemplos son o libro do médico Nóvoa Santos, R. (1916) Manual de Patología General, Santiago, El Eco Franciscano; ou a investigación do auxiliar temporal de Física, Arbaiza Basoa, J. (1928): «Aplicaciones del análisis armónico a la previsión del tiempo». Santiago. Tip. El Eco Franciscano.

9 PARGA, I. (1927), pp.7-9.

10 PARGA, I. (1978), p. 66.

11 PARGA, I. (1927), p. 7. 
Parga a diferencia da mineraloxía «...que estudia los elementos en sus combinaciones, cristales y moléculas en un mismo espacio de tiempo» ${ }^{12} \mathrm{e}$ establece que o estudio xeoquímico dun elemento debe facerse a nivel de toda a codia terrestre, non pudendo falarse da Xeoquímica de Galicia nun sentido restrinxido que, sen embargo, dálle aos seus estudios.

Máis adiante, neste primeiro apartado, explica que a Xeoquímica se trata dunha ciencia moi recente que, se ben se apoia nos datos de análises de minerais, rochas e organismos efectuados polos químicos no século XIX, está aínda nas súas primeiras fases de estudio, tanto en Europa como en América. Para rematar esta introdución, o autor refírese a diversas nocións e principios da Xeoquímica establecidos por Vladimir Vernadsky ${ }^{13}$, científico ruso considerado un dos pais desta ciencia. Este autor establece catro sistemas nos que poden atoparse os elementos químicos nun equilibrio de duración variable: os minerais, rochas, líquidos e masas gasosas; nos organismos vivos; nos fenó-

12 PARGA, I. (1927), p. 7.

13 Vladimir Ivanovich Vernadsky (San Petersburgo, 1863 - Moscú, 1945). Alumno da Universidade de San Petersburgo, onde ten entre o seus profesores de Mineraloxía a Dokuchaev, fundador da escola rusa de Pedoloxía, polo que se ve gran influenciado. Preparando a cátedra, estuda en París Química con LeChatelier e Mineraloxía con Fouqué. Esta mesma ciencia a aprende en Alemania con Groth, Sohnke e Haushofer. Desempeña a cátedra na universidade de Moscú entre 1891 y 1911, chegando a formar un dos laboratorios mellor equipados do mundo para a investigación da mineraloxía e xeoquímica. A partires de 1911 desenrola o seu traballo na Academia de Ciencias de San Petersburgo. Vive en Francia entre 1921 e 1926, período no que imparte un curso sobre Xeoquímica na Sorbona. Pioneiro no estudio da Xeoquímica e da Bioxeoquímica, tamén desenrolou diversos estudios sobre a radioactividade en minerais e rochas. No seu currículo constan máis de 100 publicacións científicas, ao longo das cales tratou de establecer un sistema teórico da Terra con varias partes interconectadas (biolóxica, xeolóxica, social e cultural) (Levit, G. (2001): BIOGEOCHEMISTRY - BIOSPHERE - NOOSPHERE. The Growth of the Theoretical System of Vladimir Ivanovich Vemadsky. Berlín, Studien zur Theorie der Biologie, Vol. 4, Verlag für Wissenschaft und Bildung, Berlin, 2001 p. 106). Entre as súas obras destacamos «La Geochimie» (Paris, 1924), na que recolleu as conferencias que impartira nun cursiño sobre xeoquímica na Universidade de París, Levit (2001), p.12. Esta obra tivo unha gran influencia en Parga, encamiñándoo ao estudo da xeoquímica. O libro, comprado por D. Isidro, aínda se conserva no Laboratorio Xeolóxico de Laxe, no seu actual emprazamento en Sada.

A información desta breve biografía de Vernadsky procede das fontes:

StAdNichenko, T. (1947), Memorial of Vladimir Ivanovich Vernadsky. American Mineralogist. Vol. 32, $\mathrm{n}^{\circ}$ 3-4, p. 181-188.

VLADIMIR IVANOVICH VERNADSKY. (2010), En Encyclopædia Britannica. Consultado o 18 de outubro de 2010, en Encyclopædia Britannica Online: http://www.britannica.com/EBchecked/topic /626269/ Vladimir-Ivanovich-Vernadsky 
menos dos magmas silíceos e no denominado «estado disperso». $\mathrm{O}$ estudo dun elemento nos catro sistemas é o que caracteriza á Xeoquímica, a diferenza da Xeoloxía e da Mineraloxía, que concentra os seus estudos principalmente nos minerais, rochas e magmas ${ }^{14}$.

O denominado por Parga «estado disperso» é de gran importancia ao seu parecer, ao existir elementos químicos cuxa maior parte se atopan neste estado de dispersión. Entre eles atópase o iodo, do que se ocupa neste traballo, estudando a súa presenza nas algas mariñas da costa galega ${ }^{15}$.

Para introducir de maneira máis detallada esta primeira publicación, este científico dedica a continuación un apartado á «Historia geoquímica del yodo». Trátase dunha información procedente na súa maior parte da obra «La Geochimie» de Vernadsky, na que Parga escribe sobre a abundancia do iodo estimada neses anos, $10^{15}$ toneladas fronte a $2 \times 10^{19} \mathrm{Tm}$ da codia, tratándose dun elemento relativamente pouco abundante, aínda que máis que o arsénico ou a prata, coa diferenza de que destes últimos coñécense centos de especies minerais mentres que do iodo apenas se coñecen tres, principalmente en forma de iodatos de calcio e sodio diseminados entre o salitre e o xeso en América do Sur. Estes minerais de iodo atópanse na capa superficial da cortiza terrestre, non existindo, segundo Parga, nas capas máis profundas un só mineral deste elemento. $\mathrm{O}$ iodo atópase na superficie da terra en estado disperso, pero é concentrado por algúns seres vivos, como as esponxas ou as algas, nas que chega a aparecer en cantidades relativamente elevadas, e que serían a orixe dos minerais de iodo que se atopan na cortiza terrestre, de forma que os compostos iodados dos organismos pasarian aos minerais, logo destruiríanse, pasando este elemento químico ao estado de átomos e ións, para volver empezar de novo o ciclo xeoquímico do iodo ao ser acumulados nos seres vi$\operatorname{vos}^{16}$.

A seguinte sección desta publicación, «Análisis del yodo en las algas de Galicia. Métodos, consecuencias y comparación de resultados», contén a parte experimental, incluíndo tamén unha explicación dos diversos métodos que existen para determinar a cantidade do elemento de estudo nas algas ${ }^{17}$, varios problemas aos que se enfrontou á hora de realizar as análises ${ }^{18}$, unha clasificación destes organismos segundo o contido en iodo e a forma na que este

\footnotetext{
14 PARGA, I. (1927), pp. 8-9.

15 PARGA, I. (1927), p. 9.

16 PARGA, I. (1927), pp. 11-13.

17 PARGA, I. (1927), pp. 15-17.

18 PARGA, I. (1927), pp. 19-20.
} 
elemento varía nas distintas partes do mesmo individuo ${ }^{19}$, a súa diferente idade e lugar de orixe ${ }^{20}$, así como a influencia que o clima ten na concentración deste elemento nas algas ${ }^{21}$. As análises foron realizadas en algas de 22 especies diferentes ${ }^{22}$, algunhas en diferentes etapas de crecemento, procedentes de 5 localidades, recolleitas entre febreiro de 1924 e agosto de $1926^{23}$. Segundo o propio Parga, era a primeira vez que en España se facía un estudo analítico comparativo do contido en iodo de diferentes algas ${ }^{24}$. Seguindo o método de incineración de Moride e perfeccionado por Fresenius haxa a porcentaxe de iodo nas plantas analizadas, á vez que defende o método utilizado fronte a outros existentes, como o de Freundler e colaboradores, por ser estes máis lentos, laboriosos e ofrecer resultados menos exactos ${ }^{25}$. Nas súas análises, Isidro procura reducir ao mínimo todas as causas que dean lugar a erros, como as diferenzas entre recoller o exemplar fresco ou arroxado polo mar, á vez que ten en conta a estación do ano, a idade, a parte analizada, etc ${ }^{26}$. Segundo estas análises, Parga atopa algo de iodo en todas as algas e divídeas en tres grupos: as ricas en iodo (con cantidades que se poden expresar en décimas por cen), as que conteñen este elemento en centésimas (estas terían 10 veces menos iodo que as do primeiro grupo e serían as máis abundantes) e unha terceira clase, as algas pobres en iodo, que o conteñen en poucos miligramos. Estas investigacións complétanse con interesantes datos, como que dentro dunha mesma especie varía a cantidade do elemento entre as diferentes partes da alga (como exemplo, na Laminaria flexicualis o iodo é máis abundante na fronde que no talo), a súa idade (o contido é maior en plantas adultas) ou o

19 PARGA, I. (1927), pp. 20-21.

20 PARGA, I. (1927), p. 18.

21 PARGA, I. (1927), p. 21.

22 As especies, segundo a nomenclatura empregada por Parga neste traballo son: Laminaria saccharina, Laminaria flexicaulis, Laminaria cloustoni, Saccorhiza bulbosa, Fucus serratus, Fucus vesiculosus, Fucus platicarpus, Halydris siliquosa, Callofilis laciniata, Heterosiphonea coccinea, Gelidium corneum, Laurencia pinnatifida, Rhodymenia palmata, Pelvetia caniculata, Chondrus crispus, Himanthalia lorea, Bifurcaria tuberculata, Ginnogongrus norvegicus, Corallina rubens, Nemaliom lubricum, Codium tomentosum e Ulva lactuca. A táboa con estes datos aparece na páxina 18 da publicación.

23 Se ben a maioría das algas foron recolleitadas en Laxe, tamén analizou mostras procedentes de Vilagarcía, Vigo, Ribadeo e Ribeira, tal como se desprende da mesma información aparecida na páxina 18, na que tamén figuran as datas de recolleita.

24 PARGA, I. (1927), p. 15.

25 PARGA, I. (1927), p. 15.

26 PARGA, I. (1927), pp. 20-21. 
lugar do que proceden (a Laminaria saccharina recollida en Vigo é máis rica no elemento estudado que outra procedente de Vilagarcía, ambas recolleitas na mesma época do ano), á vez que indica a influencia do clima na variación do contido do iodo nas algas ${ }^{27}$.

Os resultados obtidos por Parga acerca do contido en iodo das algas galegas estudadas son moi similares aos obtidos nas mesmas especies procedentes de Francia ou Escocia, datos que Parga obtén de estudos bibliográficos ${ }^{28}$.

O traballo finaliza co apartado «Abundancia de las algas en Galicia. Las industrias del Iodo» ${ }^{29}$, no que o investigador mostra a importancia económica que tería unha explotación máis eficiente do iodo en Galicia. Do mesmo xeito que sucederá con gran parte das súas seguintes investigacións, o autor mostra un gran interese polas aplicacións prácticas dos seus traballos e os seus posibles usos na industria, que permitan un desenvolvemento económico de Galicia explotando os seus propios recursos, sen ter que importar produtos que son abundantes nesta terra ${ }^{30}$.

Para comezar este último punto, explica que o uso máis frecuente das algas en Galicia é o de abono. Estimando que a produción anual destes organismos en Galicia pode chegar ao medio millón de toneladas e que só a quinta parte é utilizada polos labradores como fertilizante, quedando o resto abandonadas, que poderían ser utilizadas na industria do iodo, como sucede en Francia, Inglaterra ou Xapón ${ }^{31}$.

A continuación realiza un resume da historia do descubrimento do iodo e do seu aproveitamento na industria. $\mathrm{O}$ achado deste novo elemento anunciouse na Academia de Ciencias de París o 29 de xaneiro de 1813 e poucos anos despois empezouse a vender como curiosidade científica. É a partires de 1829, co descubrimento de que este elemento constituía un remedio contra o bocio, cando comeza unha explotación máis intensiva, que aumentou ao descubrirse novos usos deste elemento, como a súa importancia na fabricación de colorantes, explosivos, etc., chegando o seu consumo a 3000 toneladas anuais no momento da realización do traballo por parte de $\mathrm{Parga}^{32}$. Se ben Chile é o principal país produtor deste elemento a nivel mundial, as industrias francesas ou inglesas fornecen case a totalidade de iodo que se consume nos devanditos

\footnotetext{
27 PARGA, I. (1927), pp. 20-21.

28 PARGA, I. (1927), pp. 21-22.

29 PARGA, I. (1927), pp. 23-27.

30 PARGA, I. (1927), p. 27.

31 PARGA, I. (1927), p. 26

32 PARGA, I. (1927), pp. 24-25.
} 
países, mentres que en Xapón, onde levaron a cabo diversos estudos para achar os métodos máis económicos e produtivos para a súa extracción, pasouse de ser un país importador de iodo a ser un importante exportador ${ }^{33}$. Tendo en conta que as algas de Xapón son máis pobres neste elemento que as de Galicia, da explotación das algas galegas poderíase obter a totalidade de iodo que se consume en España, que era neses anos un importante importador do devandito elemento ${ }^{34}$.

En España, este traballo, ademais de ser publicado en El Eco Franciscano, tamén o foi en Arquivos do Seminario de Estudos Galegos en 1927 e este mesmo ano apareceu recollido nunha nota bibliográfica escrita por Santiago Montero Díaz en El Eco de Santiago do 7 de marzo de 1927. A importancia desta primeira investigación de Parga queda de manifesto no feito de que ademais varias revistas estranxeiras recolleron resumos desta investigación. Así, no ano 1929 apareceu en British Chemical Abstracts e ao ano seguinte no número 24 de Chemical Abstracts.

O valor deste traballo vai máis aló da súa importancia científica, tendo unha aplicación industrial, sendo consultada e empregada polos fundadores da «Sociedad Española del Yodo, S. A.» (SEYSA), que a recoñeceron como o único traballo sistemático realizado en España sobre este tema ${ }^{35}$. Neste aspecto hai que destacar que a amizade existente entre Isidro Parga e Pedro Marfany Vilarassau ${ }^{36}$ puido propiciar o desenvolvemento de SEYSA, que máis tarde continuaría o seu labor co nome de "Explotación de Algas S.A. " (EASA), fundada en 1935, da que Marfany foi director técnico e conselleiro da administración. Esta empresa tivo un especial desenvolvemento tras o ano 1938, no que se prohibiu a importación de iodo en España ${ }^{37}$.

33 PARGA, I. (1927), p. 26.

34 PARGA, I. (1927), p. 27.

35 Exposición da labor persoal, de investigación e académica efectuada polo Doutor Isidro Parga Pondal, p. 7. Arquivo do Laboratorio Xeolóxico de Laxe (ALXL).

36 Pedro Marfany Vilarassau (1909-1986). Estudou Química e Farmacia (1924-1928) en Barcelona. Máis tarde foi bolseiro durante catro meses, en Alemania para ampliar a súa formación en Química Industrial. No ano 1933 trasladouse a Madrid, onde obtivo o doutorado en Farmacia. Publicou o artigo «Una nueva fuente de obtención del iodo. Moderna obtención de iodo a partir de aguas ricas en ioduros», en Farmacia Nueva. En 1933 foi ademais socio fundador da firma PHAR S.A. (Fábrica de Productos Farmacéuticos, S. A) que tiña por obxecto a produción de iodo e de diversos produtos químico-farmacéuticos. (Dosil, F. (2007) Los albores de la botánica marina española (1814-1939), Madrid, Consejo Superior de Investigaciones Científicas, pp. 303, 314-315.

37 DosiL, F. (2007), pp. 303, 314-315. 
Na publicación do Seminario de Estudos Galegos «10 cursos de traballo, 1923 -1934», esta investigación aparece recollida como pertencente a varias seccións e subseccións. Por unha parte, dentro da Sección de Cencias Naturás, está clasificada dentro do apartado relativo ás investigacións sobre Flora. Tamén aparece na Sección de Cencias Apricadas ${ }^{38}$, no apartado «Aproveitamentos industriaes en Galicia».

As impresións do investigador acerca do seu ingreso no Seminario e a importancia nas súas posteriores investigacións foron publicadas no ano $1978^{39}$ :

Recordo a gran satisfacción que sentín despois de ter lido o traballo, nel facía, na primeira parte, algunhas consideracións sobor do ciclo xeoquímico dos elementos e que, en certa maneira, foron algo así como o xermen do que despois foi o Laboratorio de Xeoquímica que orientou unha gran parte da miña obra científica futura. Pero daquela eu non podía albiscar aínda todo esto, e si me encontraba satisfeito era mais ben porque xa me sentía perteñecente a esta famosa agrupación científico - galeguista que era o Seminario de Estudos Galegos.

A "satisfacción" que indica Parga vén dada pola alta estima na que tiña ao Seminario, dada a súa ideoloxía galeguista: «O Seminario de Estudos Galegos tiña a pesares dos seus poucos anos un prestixio enorme, un prestixio cultural, de forma que entre os estudantes e profesores mozos, sentíase a necesidade de pertenescer ao Seminario si se desexaba ser algo, ter nome, servir a Galicia» ${ }^{40}$. Este prestixio viña dado polos destacados investigadores que eran membros e pola calidade dos traballos ${ }^{41}$, que segundo Parga «implicaba a existenza duns laboratorios ou dunhas organizacións investigadoras que naquela época era ainda moi raro atopar eiquí en Galicia» ${ }^{42}$.

38 Dirixida polo arquitecto Manuel Gómez Román foi unha das últimas Secciones do Seminario en crearse.

39 PARGa, I. (1978), p. 66.

40 PARGa, I. (1978), p. 66.

41 «En el Seminario de Estudios Gallegos (...) se cobija una juventud de lo más solvente de Galicia, de lo más capacitado y de los más estudioso, (...) una juventud afectiva, vigorosa, pletórica de ansiedades nuevas, abrasada por las más nobles inquietudes». González, X. (1928), Las vacaciones del Seminario de Estudios Gallegos, El Pueblo Gallego, Vigo, 16/12/1928.

42 PARGA, I. (1978), p. 66. 


\section{ORIXES DO LABORATORIO DE XEOQUÍMICA}

A importancia de contar cunhas instalacións adecuadas para realizar as súas investigacións será un dos principais obxectivos de Parga, tanto na Universidade coma no Seminario, que se verán conseguidos en parte co establecemento do Laboratorio de Xeoquímica de Galicia da Universidade de Santiago, subvencionado polo Seminario, polo Instituto de Estudos Rexionais e máis tarde tamén pola Fundación Nacional para Investigaciones Científicas y Ensayos de Reformas (FNICER). Precursor deste laboratorio foi o laboratorio da Sección de Ciencias do Seminario, creado por proposta de Parga Pondal, seguramente sufragado por subscrición popular ${ }^{43}$. Nel leváronse a cabo algunhas das súas primeiras investigacións sobre Xeoquímica.

Nunha carta dirixida dende o Seminario á "Sociedad Unión Estradense" en outubro de 1929, na que lle agradece a axuda que está a recibir desta, o presidente do Seminario escribe: «Soñamos un bó día en ter laboratorio xeoquímico propio e non emprestado, e xa vemos brillar os tubos de ensaio e os crisoles nas mans dos químicos da Seizón que dirixe o Dr. Parga Pondal — descendente do bardo inmorredeiro - facendo análisis dos nosos minerales, estudando a sua riqueza, abrindo camiños reales á nosa industria.» ${ }^{44}$ Desta comunicación dedúcese o interese que tiña o Seminario por contar cun laboratorio de Xeoquí-

43 Mato, A. (2001), p. 64. A financiación do Seminario comezou sendo popular, para máis tarde participar Diputacións, algúns concellos e asociacións de países sudamericanos, como foi o caso da Asociación Protectora de la Cultura Gallega de Montevideo. Membros activos do Seminario, como Luis Iglesias ou o mesmo Isidro Parga actuaron como socios protectores e tamén colaboraron con cotas extraordinarias ás edicións dos dous primeiros tomos de Arquivos, revista editada polo Seminario. Non obstante os recursos económicos non debían ser os desexados. Na entrevista de González, X. (1928), terceira páxina da reportaxe, ao tesoureiro e director da Sección de Historia do Seminario, Salustiano Portela Pazos (Cóengo da basílica compostelá), explica con detalle o financiamento da entidade: «Con subvenciones desde un año ha, de tres diputaciones provinciales de Galicia; con donativos de socios protectores y los cuotas mensuales de los protectores. El total de ingresos, al año, no alcanza todavía a tres mil pesetas; cantidad insignificante para la publicación de los Archivos (el primer volumen ya en prensa), de interesantes monografías, algunas ya terminadas, adquisición de libros, gastos de material, luz, etc. (...) A medida que se vaya conociendo detalladamente la fructífera labor cultural y patriótica que aquí se realiza, sin otra mira ulterior más que la de investigar y dar a conocer las pasadas glorias y el patrimonio artístico de Galicia, aportar datos para la historia, estudiar la lengua, usos, costumbres, riqueza mineral, zoológica, etc., etc., no dudo que esta institución habrá de merecer unánimes aplausos con la eficaz colaboración de otros muchos y deseables elementos, y el consiguiente aumento de recursos económicos».

44 Documento conservado no Arquivo do Instituto de Estudos Galegos «Padre Sarmiento». 
mica propio, que non dependese exclusivamente da Universidade, tal como sucedía co laboratorio de Ciencias, e o feito de que aínda non existise formalmente a Sección de Xeoquímica ${ }^{45}$, dentro do Seminario debía de estar considerada unha parte importante da Sección de Ciencias.

Tomando como partida o ano 1926, no que o mozo profesor entra a formar parte do Seminario, entre os cursos 1926/27 e 1929/30 o autor máis produtivo de traballos monográficos foi Parga, con sete, tres deles en colaboración ${ }^{46}$. Segundo conta o mesmo Isidro, estes estudos sobre Xeoquímica poderíanse ver aínda incrementados coa colaboración de particulares sen grandes coñecementos xeolóxicos: «Quizá mi sección (sic) más que ninguna necesite de la labor de cooperación de todo buen gallego. No hace falta tener conocimientos químicos: los individuos que están en contacto con la tierra, nuestros labradores, probablemente si quisiesen, serían el factor de máxima aportación con cualquier piedra cuyas condiciones de forma o color despertasen su curiosidad $\gg^{47}$.

A partires do curso 1930/31 o Seminario establece unha maior relación coa Universidade, deixando a que fora a súa sede nos primeiros anos da organización, no antigo Colexio de San Clemente, e pasa a ocupar varios locais na planta baixa do Edificio de Fonseca. O laboratorio orixinal da Sección de Ciencias dividiuse en dous: o laboratorio de Xeoquímica e o laboratorio de Fitopatoloxía (a partir de 1933 chamado Consultorio de Plagas del Campo ${ }^{48}$ ), que xunto á súa biblioteca correspondente tiñan a súa localización na Facultade de Ciencias, no Edificio central da Universidade.

No ano 1932 (sesión do 29 de outubro) produciuse a creación da Subsección de Xeoquímica, dirixida por Isidro Parga Pondal, quedando englobada na Sección de Ciencias que continúa a dirixir Iglesias. Esta Subsección terá unha vida curta, pois na sesión do 14 de outubro de 1933, un ano despois da súa creación, pasa a chamarse Laboratorio de Xeoquímica, cunha vida autónoma da Sección de Ciencias. O propio Parga escribe o que significou para el

45 MATo, A. (2001), p. 90. Este autor sitúa na sesión do Seminario do 4 de marzo de 1933 a creación do Laboratorio de Xeoquímica.

46 MATO, A. (2001), p. 67.

47 GonZÁlez, X. (1928). Cuarta e última páxina do artigo.

48 Este laboratorio fora creado polo Seminario no ano 1926 e levaba a cabo a súa labor en coordinación coa Universidade. Subvencionado por esta, o Instituto de Investigaciones Agronómicas, a Junta para Ampliación de Estudios e o Seminario, atendía gratuitamente a consultas de particulares e entidades agrarias sobre as enfermidades das plantas de cultivo. Baixo a dirección de Iglesias, publicou diversas follas divulgativas sobre os procedimientos de loita contra diversas plagas que atacan aos vexetais, como as cochinillas ou o verme da mazá. (SEG. 10 cursos de traballo. 1923/1934, Compostela, 1934). 
a creación deste Laboratorio: «...A finales de 1933, de regreso de Alemania, me reintegré en la Universidad compostelana, donde el «Seminario de Estudios Gallegos» y el «Instituto de Estudios Regionales de la Universidad» favorecieron la continuación de mis estudios de Geoquímica, en donde, con más medios, pude continuar mis trabajos de investigación...» ${ }^{49}$.

O nacemento do Laboratorio de Xeoquímica tivo lugar grazas á colaboración da Universidade e o Seminario, que contribuíron de forma conxunta á dotación do local e medios económicos necesarios para realizar os traballos de investigación. Este feito garda relación directa coa etapa de Alejandro Rodríguez Cadarso ao frente do Reitorado da universidade compostelana, iniciada o 22 de marzo de 1930. O traballo de Cadarso como científico na Facultade de Medicina facíao coñecedor das limitacións que tiña a Universidade para levar a cabo labores investigadoras. O seu posto como deputado, á vez que reitor, unido a unha serie de cualidades, entre as que se atopaban as de ser un catedrático novo, docente implicado con profesionalidade demostrada, e espírito renovador e aperturista facilitou que puidera conseguir os presupostos necesarios para conseguir instalacións adecuadas para a investigación, o que tamén se viu favorecido polo incremento de fondos destinados á ensinanza que tivo lugar durante a Segunda República ${ }^{50}$. Se ben o reitorado de Cadarso finaliza en 1933, debido ao seu falecemento, instalacións feitas durante o seu mandato, como laboratorios e bibliotecas, permitiron que nos anos posteriores se continuara desenvolvendo unha grande actividade científica na Universidade, que se viu freada co comezo da Guerra Civil. O reitorado de Cadarso tamén permitiu un proceso de galeguización da Universidade. Cadarso, reitor progresista, galeguista e próximo ao Seminario (como mostra o feito de nomear a Armando Cotarelo como Vicerreitor) foi o creador do Instituto de Estudios Regionales (IER) e do Instituto de Estudios Portugueses, centros aos que adicou unha partida orzamentaria especial ${ }^{51}$.

A proposta do SEG, o IER estruturouse en forma de padroado, presidido polo reitor e do que eran membros compoñentes do Seminario e da Universidade. Desta última foi elixido Martín Sauras como representante da Facultade de Ciencias $^{52}$, mentres que por parte do Seminario elixiuse, a proposta de Parga, a Luis Iglesias para formar parte dese padroado, que era o encargado de xestionar a colaboración coa Facultade de Ciencias. Para a repartición dos

49 Currículo Vitae de Isidro Parga Pondal. Laxe, febreiro de 1960 (ALXL).

50 GURRIARÁn, R. (2004), pp. 208, 327, 346, 354 e 516.

51 MATO, A. (2001), pp. 111-113.

52 MATO, A. (2001), p. 112. 
cartos do IER neste centro, a Xunta da Facultade de Ciencias, na sesión do 30 de setembro de $1932^{53}$, nomeou unha ponencia formada polo decano Zurimendi, Iglesias, Parga e Martín, para que elaborasen as bases sobre as que deberían rexerse estes estudos. Na sesión do 29 de outubro de 1932 acórdase dar carácter oficial ás investigacións que tanto Parga coma Iglesias viñan realizando. Enténdese aquí que, se ben o Laboratorio de Xeoquímica non estaba establecido como tal, a mesma Facultade consideraba as investigacións de Parga como unha especialidade dentro do centro, aínda sen estar presente esa materia nos plans de estudo.

O padroado do IER decide que esta entidade debe ter como funcións principais os traballos de investigación, cursiños e conferencias, publicacións e propaganda, entre a que se atopa anuncios en prensa. Tamén se acorda que o Seminario aporte todo o traballo que leva realizando sobre esta clase de estudos e que as publicacións resultantes desta colaboración figuren como resultado do traballo na Universidade e no Seminario ${ }^{54}$.

CARACTERÍSTICAS E ACTIVIDADES DESENVOLTAS NO LABORATORIO DE XEOQUÍMICA ${ }^{55}$

Subvencionado polo IER, o Laboratorio de Xeoquímica contaba con catro dependencias, todas elas situadas no piso superior da antiga Facultade de Ciencias: un laboratorio de análise química mineral, no que podían traballar tres persoas á vez e que dispoñía dunha mesa central dobre, dúas mesas laterais e unha vitrina de extracción de gases; un cuarto de microscopía tamén con instalacións para tres persoas e no que ademais se encontraba a biblioteca e as coleccións petrolóxicas; un cuarto de balanzas, que constaba dunha balanza de análise prestada polo Laboratorio de Análise da Facultade de Ciencias; e un cuarto de espectrografía. Se ben o director do Laboratorio nomea esta última dependencia desta forma, aínda no ano 1936 estaba baleira, á es-

53 Libro de Actas da Facultade de Ciencias (1904-1935). Arquivo Histórico da Universidade de Santiago (AHUS).

54 MAto, A. (2001), pp. 112 - 113. Esta última condición explica que as investigacións realizadas por Parga Pondal unha vez establecido o Instituto de Estudios Regionales figuren como feitas no Laboratorio de Geoquímica del SEG y de la Universidad, nome que pode dar lugar a equívocos, cando en realidade se trataba da mesma dependencia.

55 A base principal deste apartado provén do documento Informe sobre el Laboratorio de Geoquímica de la Universidad de Santiago, por el Director del mismo Dr. I. Parga-Pondal, firmado polo propio Parga o 21 de xuño de 1935 e conservado no ALXL. 
pera dun espectrógrafo e outros aparatos necesarios para realizar análises espectrais, tanto cuantitativos como cualitativos, de grande importancia para as investigacións que se levaban a cabo no Laboratorio.

Entre o material co que contaban para as investigacións destacaba un gran microscopio de polarización da prestixiosa casa Leitz, utilizado para estudos petrográficos e que se comprara no ano 1933 polo Instituto de Estudos Regionales. Un ano antes, o SEG comprara para o Laboratorio un crisol de platino. Deste mesmo elemento existía diverso material que comprara o director do Laboratorio por ser indispensable para os seus traballos, como outros crisois, pinzas con puntas de platino, unha cápsula grande, etc.

A escaseza de medios cos que contaba este centro de investigación facía que nos seus inicios non tivese en propiedade nin o material básico para traballar, non posuíndo matraces, tubos, cápsulas de vidro nin reactivos propios, polo que era necesario utilizar os materiais e produtos do laboratorio de Química Analítica, materia da que Parga era profesor auxiliar na Facultade de Ciencias. Estas limitacións ás que se enfrontaba o Laboratorio non se daban en canto ao material a investigar, xa que posuía unha importante colección de rochas españolas, na súa maioría galegas, que foran recollidas e clasificadas polo director do Laboratorio. Estas mostras, ás que se unían coleccións mineralóxicas, permitiron rectificar os mapas xeolóxicos existentes, constituíndo un índice de rochas e minerais de gran valor. Das rochas existentes, Isidro realizara preparacións microscópicas durante a súa estanza en Alemaña, xa que, como vimos, o Laboratorio non contaba cunha máquina para esta función. Dende o Laboratorio, Parga trataba de establecer contacto con museos españois e estranxeiros cos que realizar intercambios, coa intención de completar as coleccións petrolóxicas. Ademais destas existía unha importante recompilación de mostras de areas de praias galegas que unha vez estudadas terían un gran valor científico e industrial.

A biblioteca do Laboratorio, situada no mesmo cuarto que as coleccións de estudo, contaba no ano 1936 con máis de 300 volumes de obras relacionadas cos temas de investigación. A compra deste material bibliográfico fora sufragada polo Seminario e polo propio Parga. Como exemplo, en xaneiro de 1936 o SEG compraba as revistas Boletín y Memorias del Instituto Geológico de España, Memorias explicativas del mapa geológico de España, $1: 50000 \mathrm{y}$ Anais da Facultade de Ciencias da Universidade do Porto, mentres que Parga, por suscripción particular, recibía Sweizerisches Mineralogisches und Petrographisches Mitteilungen, Anales de la Sociedad Española de Física y Química e o Boletín de la Sociedad Española de Historia Natural. En varias destas revistas ás que estaba subscrito o Laboratorio ían aparecendo os resul- 
tados das investigacións que nel se desenvolvían. Os traballos levados a cabo nas súas instalacións, e que se pensaban continuar durante 1936, poden dividirse en dous grupos moi relacionados entre si:

1. Investigacións de carácter científico. Entre estas investigacións destaca o estudo das diferentes series de rochas eruptivas e metamórficas do macizo Galaico-Duriense, traballo levado a cabo dende múltiples aspectos debido á súa complexidade, pero non coa profundidade necesaria pola falta de medios. As principais vías de investigación que se levaban a cabo eran a diferenciación dos granitos, gabros e peridotitas; o estudo dos lamprófidos e outras rochas filonianas básicas; a orixe e extensión da pegmatita e de diversos minerais de interese que a forman, como berilo, espodumena, casiterita, wolframita, etc.; problemas do metamorfismo das rochas da rexión Galaico-Duriense; orixe e formación das anfibolitas; distribución dos elementos escasos nos magmas; estudo dos minerais que forman as areas resistentes á alteración; o proceso da alteración das rochas no macizo Galaico-Duriense e a súa posible relación co clima; a formación do caolín, etc.

Testemuña do inicio destes estudos é a colección de rochas de Galicia deste investigador que está exposta no Museo de Historia Natural da Universidade de Santiago de Compostela ${ }^{56}$. Trátase dunha colección formada por rochas metamórficas na súa maioría (anfibolitas, gneises, xistos,...), pero que tamén conta con numerosos exemplares de rochas plutónicas (gabros, dioritas, granitos,...), mentres que son escasas as rochas filonianas (pegmatitas, lamprófidos, pórfidos...). As máis de 500 mostras que a conforman, pertencentes a 118 tipos de rochas, proceden na súa gran maioría de localidades pertencentes á rexión Galaico-Duriense, tanto da provincia da Coruña (Santiago de Compostela, Tordoia, Padrón...) coma de Pontevedra (Salvaterra de Miño, Porriño, Vilagarcía...). Foron recollidas entre o 3 de abril e o 11 de xullo de 1936 e son resultado dunha continuación da excursión que Parga realizara un ano antes co Seminario polas terras do Deza, coa intención de realizar un estudo xeoquímico da rexión. Tal como relatan García et al. ${ }^{57}$, a recollida de mostras viuse interrompida pola Guerra Civil, como se pode deducir da data na que foron recollidas as últimas mostras. As rochas quedaron gardadas na Universidade

56 Esta colección é a única que se conserva na Universidade de Santiago que está formada por exemplares recollidos polo propio Parga e que é resultado das investigaciones do Laboratorio de Xeoquímica.

57 GARcía, C. et al. (2002), O coñecemento da xeoloxía de Galicia a través das pegadas de Isidro Parga Pondal no Museo de Historia Natural da Universidade de Santiago, Actas do VII Coloquio Galego de Museos, pp. 155-164. 
compostelá durante case 70 anos envolvidas nos papeis de xornal cuxas follas recollían os tráxicos acontecementos acontecidos no ano 1936. Ao realizarse o proceso de catalogación actual desta colección púidose comprobar que, se ben todas elas conservan o código do itinerario e o nome do lugar de recollida, máis da metade das rochas quedou sen identificar por Parga Pondal, o que demostra que os estudos que se propoñía realizar sobre o macizo Galaico-Duriense quedaron interrompidos nas súas fases máis temperás.

2. Estudos de aplicación práctica: investigacións relacionadas para o posible establecemento de industrias que aproveitasen os minerais ou elementos de interese, que non foran considerados previamente pola idea errónea da súa escaseza ou porque os seus usos na industria eran de recente incorporación. Destaca o estudo dos minerais que conteñen metais raros, como zircón, titanio ou torio, pola súa grande importancia económica, e as investigacións sobre as arxilas de Galicia e as súas propiedades plásticas, punto de fusión, condicións óptimas de fusión, etc., por considerar Parga a importancia destes materiais para o desenvolvemento dunha industria cerámica, que naqueles anos estaba moi atrasada. Deducimos que os coñecementos adquiridos durante estes estudos seranlle de grande axuda a Parga nos seus diferentes postos de traballo ocupados despois de 1936, tanto na empresa Kaolines de Lage como en Titania S.A.

Outra das tarefas que se levaba a cabo no Laboratorio era a de analizar ou estimar o valor económico, os posibles usos ou a importancia dos produtos minerais que lle fosen remitidos, cousa que viña facendo dende 1934, de forma similar ao que Iglesias realizaba no seu Consultorio de Pragas do Campo, onde resolvía dúbidas e consultas acerca da importancia que certos insectos podían ter na economía dos cultivos.

UN PASO IMPORTANTE NA VIDA DO LABORATORIO: A AXUDA DA FNICER

O IER e o Instituto de Estudos Portugueses viviron un gran descenso na súa actividade tras o falecemento do seu creador, Rodríguez Cadarso. O novo reitor, Ricardo Montequi, que fora vicerreitor co seu predecesor dende maio de 1931, foi elixido como sucesor de Cadarso o 20 de xaneiro de 1934. Montequi comezou o seu mandato cunhas liñas de xestión continuístas pero, principalmente polo contexto político, marcado polos acontecementos de Asturias e os gobernos do Bienio negro, unido á ideoloxía de Montequi, liberal aínda que cun compromiso galeguista moito menor que Cadarso, tiveron como con- 
secuencia unha redución no presuposto dedicado aos estudos rexionais ${ }^{58}$. Non obstante isto non significou o fin do Laboratorio de Xeoquímica, pois continuou contando co apoio económico da Universidade e do Seminario, ao que se uniría, a partir do ano 1935 a axuda económica da FNICER ${ }^{59}$. Esta colaboración produciuse logo de solicitude de Parga de «ensanchar os traballos de Xeoquímica que viña realizando ${ }^{60}$. Tal como recollen as Actas do Consello de Administración da FNICER, o 24 de xaneiro de 1935 a súa petición foi aceptada, producíndose o ditame favorable de Antonio Madinaveitia, vogal do Consello de Administración da Fundación, aprobándose a concesión de 7500 pesetas para o primeiro trimestre do ano ${ }^{61}$, condicionada a que a Universidade de Santiago declarase a súa conformidade. O oficio da FNICER no que se lle informaba a Parga da concesión deste apoio foi asinado en Madrid o 28 de marzo de 1935 por José Castillejo, o seu director administrativo e á vez Secretario da JAE, e dicía:

La Fundación Nacional, autorizada por su Consejo de Administración, ha resuelto organizar y sostener, bajo la dirección de usted, y en consideración a su preparación y aptitudes, un Laboratorio de Geoquímica para el estudio e investigación de problemas, tanto de ciencia pura como de aplicación, especialmente aquellos que afecten a nuestro suelo.

Si la Universidad de Santiago presta de modo expreso su conformidad y facilita los locales necesarios a juicio de Vd., así como el suministro de agua, luz y fuerza, la Fundación considerará un honor tener en esa Universidad un centro de investigaciones como los que ya sostiene en otras.

58 GURRIARÁN, R. (2004), p. 354.

59 Creada o 13 de xuño de 1931 e cunha vida de só catro anos, a Fundación Nacional para Investigaciones Cientificas y Ensayos de Reformas foi un centro moi vinculado á JAE. Tiña como obxectivo promover o desenvolvemento tecnolóxico de España, descentralizar a actividade científica e actuar de conexión entre a investigación e a empresa. Foi dirixida por José Castillejo, secretario da JAE, que contou con expertos en diversas áreas que valoraban os proxectos que se lle presentaran solicitando axudas económicas. No ano 1934 comezou a crear laboratorios en provincias, chegando a establecer oito en diversas universidades: Histoloxía e Cultivo de Tecidos (Valladolid), Química Orgánica e Xenética (Salamanca), Embrioloxía (Cádiz), Xeoquímica (este creado grazas á Universidade de Santiago e ao SEG, como dixemos), Análise Metalúrxica (Oviedo), Hematoloxía (Zaragoza), ademais de renovar un laboratorio de Funcións en Valencia.

60 Formentín, J. e RODRÍGUEZ, E. (2001), La Fundación Nacional para investigaciones científicas (1931-1939) Actas del Consejo de Administración y Estudio Preliminar. Madrid, Consejo Superior de Investigaciones Científicas, pp. 168, 176, 186.

61 Para o segundo semestre de 1935 o orzamento aprobado para o Laboratorio foi de 15000 pesetas (Formentín y Rodríguez, (2001), p. 176). 
La Fundación exige de usted una dedicación plena al Laboratorio, incompatible con cualquiera otra ocupación oficial y privada, excepto la función docente en la Universidad, y le ofrece a usted una retribución anual de CINCO MIL pesetas, durante tres años, pasados los cuales se adoptarán acuerdos a la vista de los resultados obtenidos.

A propuesta de usted y dentro de los recursos que cada año presupueste, abonará la Fundación el material indispensable para el Laboratorio y una o dos becas para jóvenes que, habiendo terminado sus estudios universitarios o próximos a terminarlos, quieran formarse en aquella especialización científica.

Si Vd. acepta estas condiciones y se sirve devolverme un ejemplar de este oficio consignándolo así y añadiendo en su caso la conformidad del Sr. Rector o del Sr. Decano, recibirá usted instrucciones para comenzar inmediatamente los trabajos ${ }^{62}$.

Desta comunicación destacamos dous puntos. Por unha parte o obxectivo que debía ter o Laboratorio, isto é, que os traballos realizados nel fosen de ciencia pura pero tamén de aplicación, en consonancia cos obxectivos da FNICER de conectar a investigación realizada nos laboratorios que se establecían baixo a súa axuda coa aplicación industrial, co obxectivo de conseguir unha modernización tecnolóxica de España. Por outra, a Fundación só sufragaba os gastos indispensables para o material do Laboratorio e para unha ou dúas bolsas para mozos, debendo correr cos gastos de luz e auga a Universidade de Santiago, condición esta sen a cal non sería concedida a axuda.

Esta comunicación da FNICER foi lida por Parga na reunión da Xunta da Facultade de Ciencias o día 9 de abril de 1935 e un día despois ${ }^{63}$, o Decano Zurimendi, acepta a condición de subministrar «luz, gas y fuerza» para o devandito Laboratorio, como viña facendo nos anos previos, tal como explica Zurimendi na resposta á comunicación lida polo beneficiario da axuda, e que forma parte do oficio que este mandaría á Fundación:

...me es muy grato manifestar a usted que acepto, honrándome con ello, todas las condiciones que en el mismo se expresan, y que la Facultad de Ciencias de esta Universidad de Santiago ha cedido gustosa, en junta celebrada el día de ayer, los locales necesarios para la instalación de las diferentes dependencias de dicho Laboratorio de Geoquímica, y que en parte ya venían funcionando bajo mi dirección (sic), así como también se halla dispuesta a seguir suministrando por su cuenta, y como hace en la actualidad, los servicios gas, luz y fuerza...

O feito de que a Facultade de Ciencias facilitase o que a Fundación solicitaba non é de pouca importancia, dada a grave situación económica pola que

62 Documento conservado no ALXL.

63 Libro de Actas da Facultade de Ciencias (1904 - 1935). AHUS. 
estaba a pasar a Universidade, tal como recollen as actas de Xunta da Facultade de Ciencias neses anos. Como exemplo, o 21 de decembro de 1933, o mesmo Isidro, consciente da penuria económica do centro, insiste no alto custo da electricidade, acordándose nesta Xunta, por solicitude de Parga, solicitar ao reitorado que negocie coa compañía eléctrica para obter unha tarifa especial para a Universidade e en especial para a Facultade de Ciencias. Estas xestións non darán resultado e o problema prolongarase no tempo, como demostra o feito de que na sesión do día 9 de maio de 1935 se indique que as xestións do reitor coa compañía de electricidade non deran resultados satisfactorios, engadíndose a iso o problema que a voltaxe da rede que tiña a Facultade era moi inferior ao oficial. Isto causaba que o motor destinado a accionar a bomba de elevación de auga non funcionase, o que obrigou á acometida de auga da compañía de augas potables de Santiago, xa que se non os traballos que se estaban a levar a cabo nos laboratorios terían que ser interrompidos ao non chegar a auga aos pisos superiores.

Unha vez que a Universidade accedeu a correr con todos os gastos necesarios, o Laboratorio empezou a recibir a axuda económica da FNICER, grazas á cal puido funcionar de xeito case independente do resto dos laboratorios da Facultade de Ciencias, permitíndolle contar con material propio. A factura máis antiga que se conserva no ALXL que faga referencia á compra de material para o Laboratorio, pagado grazas á subvención da FNICER, ten data 30 de xaneiro de 1936 e o seu importe ascende a 441 pesetas. Nela podemos observar a gran limitación de recursos cos que contaba o Laboratorio antes da devandita axuda, pois gran parte do pedido era material básico, que foi mercado na casa de material científico «Establecimientos y vidrieras Llofriu S. A.» ${ }^{64}$ :

5 triángulos de cuarzo opaco con alambre de $35 \mathrm{~mm}$.

4 triángulos de cuarzo opaco con alambre de $45 \mathrm{~mm}$.

2 triángulos de cuarzo opaco con alambre de $55 \mathrm{~mm}$.

10 mecheros Bunsen para gas Benoid con regulador de aire.

2 desecadores Scheibler con tapa a botón y disco de porcelana de $12 \mathrm{~cm}$.

3 desecadores Scheibler con tapa a botón y disco de porcelana de $14 \mathrm{~cm}$.

64 Empresa fundada en Barcelona no ano 1860 e que en 1936 contaba con catro establecementos: un na súa cidade de fundación, dous en Madrid e o cuarto en Palma de Mallorca. Ao longo da súa historia esta empresa fora gardoada con grandes premios en varias exposicións, como nas internacionais de Sanidade de 1932 e 1933. «Establecimientos y Vidrieras Llofriu S.A.» contaba con fábricas de medio cristal e vidro hoco, especializada en frasquería e botellería, e realizaba instalacións completas de laboratorios, vendendo produtos químicos puros para análises e material para farmacias. Información extraída das facturas do material mercado por Parga para o Laboratorio de Xeoquímica, conservadas no ALXL. 
1 cristalizador fuerte con bordón vuelto de $215 \mathrm{~mm}$ de diámetro.

1 mortero de ágata con mano de $80 \mathrm{~mm}$.

6 soportes de hierro pie trípode de $55 \mathrm{~cm}$. de altura variable.

6 aros de hierro fundido con nuez de $10 \mathrm{~cm}$ de diámetro exterior.

2 cápsulas de porcelana fondo semi - plano de $167 \mathrm{~mm}$. con pico, marcha flecha.

2 cápsulas de porcelana fondo semi - plano de $150 \mathrm{~mm}$. con pico, marcha flecha.

2 crisoles con placa filtrante Jena modelo lG3

2 frascos densidades para sólidos de 30 gramos.

No segundo pedido, cuxa factura ten data do 26 de marzo de 1936, infórmase do envío de novo material como máis chisqueiros Bunsen para gas normal, que o mesmo Isidro se encargaba de adaptalos para gas Benoid (o empregado no Laboratorio), dous aparatos de baño maría Víctor Meyer, de cobre con nivel constante, discos de porcelana e embude de cristal, de $16 \mathrm{~cm}$. de diámetro e a gas, que constitúen o material máis caro comprado ata a data, xa que entre os dous custaron 140 pesetas. Ao mes seguinte, realízase unha nova compra, esta vez máis numerosa, pero tamén constituída, na súa maior parte, de instrumental imprescindible para as tarefas experimentais que Parga realizaba como tubos de ensaio ou probetas de distintas características.

A axuda da FNICER tamén permitiu ao Laboratorio de Parga acceder a publicacións ás que antes non lle era posible debido ao seu alto prezo. Desta forma, o Laboratorio subscribiuse e comprou todos os números atrasados da revista sobre temas xeoquímicos Chemie der Erde, e fíxose cargo da subscrición de Sweizerisches Mineralogisches und Petrographisches Mitteilungen, que ata entón fora sufragada polo propio director do Laboratorio.

Resultado da axuda económica da FNICER, Parga realizou as seguintes investigacións, publicadas nas revistas que seguen ao título do traballo: «Arena monacítica en la ría de Arosa» (1935). Anales de la Sociedad Española de Física y Química. Tomo 33, p. 466. «Sobre la presencia de arenas monacíticas en las costas gallegas» (1935). Boletín de la Academia de Ciencias Exactas, Físicas y Naturales de Madrid. Tomo I, $\mathrm{n}^{\circ}$ 2, p. 16. «Ensayo de clasificación cronológica de los granitos gallegos» (1935). Conferencia pronunciada na Universidade do Porto, na Semana Galega do Porto celebrada no ano 1935, publicada en Anais da Facultade de Ciencias do Porto, tomo XX, e en Reseñas cientificas de la Sociedad Española de Historia Natural, tomo X, p. 27. «Beiträge zur kenntnis einiger jungvulkanischer gesteine spaniens» (1935). Sweizerisches Mineralogisches und Petrographisches Mitteilungen. Tomo 15, páx. 266. «Quimismo de las manifestaciones magmáticas cenozoicas de la Península Ibérica» (1935). Trabajos del Museo Nacional de Ciencias Naturales de la Junta para Ampliación de Estudios, Serie xeolóxica, n. ${ }^{\circ}$ 39, Madrid, agosto de 1935, 174 p. 
Ademais destes traballos, durante o ano 1935 iniciáranse outras investigacións no Laboratorio, algunhas das cales se pensaba continuar durante o ano 1936. Entre elas encontrábanse novos traballos de Parga xunto ao profesor Burri sobre os fenómenos de contacto das andesitas do Cabo de Gata e as erupcións de Melilla e Chafarinas ${ }^{65}$. Para estas investigacións utilizaban rochas das coleccións de diversos museos europeos entre os que se encontraba o Museo de Ciencias Naturais de Madrid. ${ }^{66}$

A axuda da FNICER, tal como explicaba a comunicación da concesión que enviara a Parga, permitiu ao Laboratorio contar con bolseiros para que colaborasen nas tarefas de investigación. Entre eles encontrábase Pedro Brañas Cancelo $^{67}$, que traballou xunto a Isidro nun estudo acerca das ilmenitas dos depósitos aluviais das costas galegas. Esta investigación tiña un interese que ía máis alá da parte teórica, enmarcándose dentro dos traballos de aplicación práctica do Laboratorio, pola posible utilización industrial do titanio, cuxos usos industriais coñecidos eran cada día maiores. Por este motivo se estaba a elaborar unha memoria que levaría por título «La industria del titanio, su posibilidad e importancia en Galicia» en cuxa elaboración colaborou Juan Martínez Núñez sobre as posibilidades desta industria que utilizaría como materia prima as ilmenitas galegas, e que sería pioneira en España ${ }^{68}$. Estas investigacións sobre o titanio serán a base da industria «Titania, S.A.» na que traballará Parga tras a súa expulsión da universidade compostelá.

Durante o ano 1936 e dentro das actividades do Laboratorio, Parga tamén tiña intención de continuar cos traballos iniciados o ano anterior, no que realizara un estudo xeoquímico da bisbarra da Terra do Deza (Pontevedra) como parte do estudo que estaba a realizar o SEG. Outros dos plans que Isidro tiña pensado continuar era a publicación de varias investigacións realizadas xunto a alumnos da Facultade de Ciencias sobre diferenciacións magmáticas en granitos e outras rochas galegas, así como outros sobre a composición química de minerais raros que foran encontrados e se recolleran durante varias excursións

65 Isidro comezara a traballar con Burri durante a súa na Eidgenössische Technische Hochschule de Zurich, y con el xa publicara dous artigos sobre a petroquímica das rochas volcánicas españolas.

66 Informe sobre el Laboratorio de Geoquímica de la Universidad de Santiago, por el Director del mismo Dr. I. Parga-Pondal,(1935). ALXL.

67 Brañas Cancelo non chegaría a completar os seus estudos de Ciencias antes da Guerra Civil, durante a que foi Teniente provisional de Infantería. Expediente de Pedro Brañas Cancelo no AHUS.

68 Juan Martínez Núñez traballaría máis tarde xunto a Isidro en «Titania S.A», como enxeñeiro xefe da mina. 
organizadas dende o Laboratorio. Entre estes traballos proxectados encontrábanse «Composición química de las ilmenitas de las playas gallegas», xunto ao bolseiro do Laboratorio, Brañas Cancelo, e «La diferenciación magmática de la mancha granítica de Ponteareas»), xunto a Isidro Suárez $\mathrm{Paz}^{69}$. Ningunha destas dúas investigacións chegaría a ver a luz, ao verse cortada a actividade do Laboratorio pola sublevación facciosa que desembocaría na Guerra Civil.

Outra da documentación que se conserva do Arquivo do Laboratorio de Xeoquímica no ALXL son as contas de gastos do Laboratorio entre abril de 1935 e xuño de 1936. A partir delas podemos coñecer o soldo mensual que tiña o director do Laboratorio, que ascendía a 416,66 pesetas e a cantidade que percibía o bolseiro, 166,66 pts., constando a existencia de só un destes axudantes durante este período. A estes gastos sumábanse outros, como os pertencentes a pagamentos a casas de material científico.

Tamén se conserva un listado das cantidades que a FNICER ingresou durante o mesmo período na conta que o Laboratorio de Xeoquímica tiña no Banco Hispano-Americano. As cantidades subministradas pola FNICER parecían ir en aumento cada ano, tal como indica a diferenza entre as contías dos meses de maio de 1935 (397,17 pts.) e 1936 (1370,13 pts.), incremento seguramente debido á grande actividade que desenvolvía o Laboratorio.

Aínda contando coa axuda económica da FNICER, o Laboratorio tiña importantes limitacións que impedían un estudo máis amplo en moitas investigacións. As necesidades máis urxentes eran de dous tipos: material necesario para realizar as investigacións (dende o instrumental máis básico a aparatos para realizar diversas funcións) e revistas e obras de consulta ${ }^{70}$. Dentro do primeiro grupo, o director do Laboratorio consideraba de especial importancia contar cun espectrógrafo de cuarzo con gran poder de dispersión para realizar análises cualitativas e cuantitativas, requirindo tamén para estes últimos un fotómetro termoeléctrico. Para a instalación destes aparatos Parga xa sinalara a existencia dun cuarto, tal como sinalamos, que designara co nome de cuarto de espectrografía. Outras das demandas de Isidro para un mellor fun-

69 Isidro Suárez Paz (n. Vigo, 1906) licenciárase en Ciencias en 1933. Alumno de Fernando Calvet e axudante nas clases prácticas da asignatura de Análisis Químico na Facultade de Ciencias hata o ano 1936. Traballou en Zeltia, onde entrou grazas a Calvet (Gurriarán, 2004, p. 516). Foi vocal e máis tarde Vicedecano do Ilustre Colexio Oficial de Químicos de Galicia.

A información dos traballos que Parga tiña pensado continuar proceden do documento Informe sobre el Laboratorio de Geoquímica de la Universidad de Santiago, por el Director del mismo Dr. I. Parga-Pondal, (1935). ALXL.

70 Segundo narra o propio Parga nun Informe do Laboratorio de Xeoquímica da Universidade de Santiago enviado á FNICER no que explica o traballo investigador realizado e as necesidades do Laboratorio (ALXL). 
cionamento do Laboratorio era a de contar cun forno eléctrico de resistencia de varas de carborundo e que alcanzase unha temperatura de $1250^{\circ} \mathrm{C}$, especialmente necesario para os estudos de cocción das arxilas. Para medir con precisión a temperatura do forno Parga tamén consideraba necesario contar cun pirómetro termoeléctrico.

Ademais dos aparatos xa citados, considerados de gran necesidade, o Laboratorio tamén requiría doutros, que permitirían unha maior rapidez e exactitude nos traballos realizados. Entre esta aparataxe solicitada encontrábase unha máquina de facer preparacións microscópicas de rochas ou unha balanza rápida de lectura directa. Destas solicitudes, autorizouse a adquisición do forno eléctrico e do pirómetro termoeléctrico, e aprazouse a compra do espectrógrafo de cuarzo e do fotómetro termoeléctrico ata que fosen indispensables ${ }^{71}$.

O Laboratorio tamén requiría contar con material bibliográfico actualizado para coñecer as investigacións recentes realizadas no campo da Xeoquímica, se ben Isidro se enfrontaba ao problema do alto custo das obras e revistas importantes. Grazas á colaboración da Fundación puidérase acceder a varias publicacións, tal como se mencionou, mais no ano 1936 Parga solicitou poder contar tamén coa revista da Sociedade Alemá de Mineraloxía Fortschritte der Mineralogie, Kristallographie und Petrographie así como de importantes tratados e obras fundamentais que non estaban presentes na biblioteca do Laboratorio, polo seu elevado prezo e os limitados recursos cos que contaba este centro de investigación ${ }^{72}$.

Por todas estas causas, Isidro solicita á FNICER a principios do ano 1936 a cantidade de 6000 pesetas anuais, como cantidade necesaria para un bo funcionamento do Laboratorio, diñeiro que se repartiría entre a compra de material funxible, os gastos do material de laboratorio e a parte que iría destinada aos bolseiros. A concesión da solicitude viuse reflectido no aumento de presuposto para o Laboratorio, que no segundo trimestre de 1936 recibiu 7500 pesetas ${ }^{73}$.

Tras o visto e prace da Fundación e o conseguinte incremento dos recursos económicos, que posibilitaron cumprir as peticións de Parga, a actividade do Laboratorio durante os primeiros meses de 1936 foi intensa, véndose cesada polo comezo da Guerra Civil, segundo Parga ${ }^{74:}$ " Cuando las actividades del laboratorio de Geoquímica de Santiago eran máximas, su trabajo quedó inte-

71 GURRIARÁN, (2004), pp. 162, 163.

72 Informe sobre el Laboratorio de Geoquímica de la Universidad de Santiago, por el Director del mismo Dr. I. Parga-Pondal, (1935). ALXL.

73 Contas do Laboratorio de Xeoquímica. ALXL.

74 C.V. de Isidro Parga Pondal, (1960). ALXL. 
rrumpido bruscamente por los acontecimientos políticos que se desarrollaron a partir de Julio de 1936».

O Laboratorio de Xeoquímica levou a cabo importantes traballos acerca de análise de rochas e minerais e froito dos traballos realizados por Parga publicouse a existencia de varios minerais novos para España. Tamén colaborou en traballos máis amplos, como a elaboración do mapa xeolóxico da Terra do Deza, e coa Misión Biolóxica de Galicia e os servizos de Repoboación Forestal, para os que realizou diversas análises de terras. Durante a súa existencia contou co apoio do Instituto Xeolóxico e Mineiro de España, que fixo importantes doazóns de libros ${ }^{75}$.

\section{CONCLUSIÓN}

A través destes parágrafos puidemos observar como Isidro Parga Pondal, grazas á súa propia iniciativa, foi creando un importante centro de investigación na Universidade, primeiro contando só coa axuda económica desta, logo sumouse a do Seminario de Estudos Galegos e finalmente a da FNICER, dada a importancia que conseguiu o Laboratorio a nivel de España. No Laboratorio de Xeoquímica da Universidade de Santiago, Parga iniciou na investigación a varios dos seus alumnos, que máis tarde foron profesores, realizou investigacións que posteriormente serían de grande interese, como o caso dos estudos sobre o titanio e as súas materias primas, á vez que estableceu unha forma de traballar, aprendida durante as súas estanzas no estranxeiro, que se vería continuada no Laboratorio Xeolóxico de Laxe, continuador, en certo xeito, do Laboratorio de Xeoquímica da Universidade de Santiago.

Recibido: 3 de marzo de 2011

Aceptado: 7 de julio de 2011

75 SEG, 10 cursos de traballo. 1923 - 1934. Compostela, 1934. 